\title{
Erratum
}

\section{Pulsed dielectric spectroscopy of supercooled liquids}

\section{R. Böhmer, B. Schiener, J. Hemberger}

Institut für Festkörperphysik, Technische Hochschule, D-64289 Darmstadt, Germany

Z. Phys. B 99, 91 (1995)

Due to a typesetting error several equations were printed incorrectly.

Equation (18) should read

$P(t) \approx \chi t_{1} \Delta E \varphi(t)$.

Equation (23) should read

$\left\langle\log _{10} \tau\right\rangle_{\delta}=a^{-1} \int \log _{10} \tau A_{B}(\tau) \mathrm{d} \log _{10} \tau \equiv \log _{10} t_{1}-\Delta(\delta)$.

In Sect. 4.3.2 the expression for $A_{2 \max }$ shoûld read

$A_{2 \max }=\Delta E_{3}+\Delta E_{2} \rho^{-1 / \delta} \delta /(1+\delta)^{1+1 / \delta}$. by the European Physical Society and supported by the publisher. This program is funded by INTAS, the international association for the promotion of cooperation with scientists from the independent States of the former Soviet Union. Members of INTAS are the European Union, Austria, Belgium, Denmark, Finland, France, Germany, Greece, Ireland, Italy, Luxembourg, The Netherlands, Portugal, Spain, United Kingdom and Switzerland. (INTAS, rue du Luxembourg 14A, 1040 Bruxelles, Belgique). 